\title{
Páramos y La foto del invernadero de Reina María Rodríguez: la formación de un sujeto individual y colectivo
}

Este artículo analiza dos colecciones de poesía, Páramos (1995) y La foto del invernadero (1998), de la poeta cubana Reina María Rodríguez. Se enfoca en la formación de la subjetividad de la voz poética, un proceso que se lee a través del pensamiento de Julia Kristeva. A través de tal desarrollo, se sostiene que la voz poética forma conexiones con otros personajes en su poesía; es más, se nota que estos procesos poéticos se asemejan a las comunidades creadas por la poeta misma. El artículo propone que, en esta comunidad, la voz poética juzga su contexto, la ciudad de la Habana en los años noventa, el Período Especial en Tiempos de Paz.

Palabras clave: literatura cubana, psicoanálisis, Julia Kristeva, Reina María Rodríguez, feminismo

This article analyzes two collections of poetry, Páramos (1995) and La foto del invernadero (1998), by the Cuban poet Reina María Rodríguez. It analyzes the poetic voice's development as a subject, primarily through the work of Julia Kristeva. Through this development, the poetic voice builds connections with other characters. Moreover, these poetic processes relate to the communities the poet herself created in her context, Havana in the I990s. The article proposes that, in this community, the poetic voice then judges her context, the Special Period.

Keywords: Cuban literature, psychoanalysis, Julia Kristeva, Reina María Rodríguez, feminism

Reina María Rodríguez es una de las poetas cubanas mejor conocidas fuera de la Isla. ${ }^{I}$ Ha publicado varias colecciones de poesía, y fragmentos de su obra aparecen en diversas antologías. ${ }^{2}$ Su poesía está inspirada en distintas fuentes, desde las actividades cotidianas hasta el pensamiento postmoderno. 3 Dos colecciones, Páramos (1995) y La foto del invernadero (1998), merecen atención especial porque llevan al lector desde la rutina diaria hacia lo universal. Tratan de temas poco tradicionales, tales como los cambios del cuerpo femenino y la experiencia erótica desde el punto de vista 
de la mujer. En consecuencia, se puede hablar de estos poemas como personales, aunque la poeta mantiene una mirada objetiva en ellos (Rodríguez, "Desire").

Este artículo propone una exégesis de la poesía de Rodríguez en estas dos colecciones. El análisis se enfoca en la formación de la voz poética. Debido al hecho de que las dos colecciones de poemas son de carácter personal, exhiben un punto de vista similar y tratan del cuerpo de la voz poética, su pareja, su comunidad y su contexto, considero que los poemas son de la misma voz poética. En Páramos y La foto del invernadero, a mi modo de ver, la voz poética se desarrolla como sujeto siguiendo algunos de los pasos expuestos por la psicoanalista feminista Julia Kristeva: la chora, lo abyecto y el espejo.4 A través de elementos corporales que quedan fuera de su control, le es posible formar conexiones con otros, y juzgar su contexto, la ciudad de la Habana en el Período Especial en Tiempos de Paz en los años noventa.5 Se realiza el análisis de esta parte de la obra de Rodríguez a partir del concepto de arte y tejido social desarrollado por la crítica feminista chileno-francesa, Nelly Richard.

En Páramos y La foto del invernadero, la voz poética medita sobre su vida en un espacio doméstico que se asemeja a la etapa de la chora en el pensamiento de Kristeva. Es más, la poesía refleja una influencia de la sangre y menstruación. De ahí sigue su búsqueda al considerar su reflejo en el espejo y una foto de una joven - posiblemente de sí misma - en una etapa similar a la del espejo, pero que ocurre en la vejez. La voz poética reconoce su fragilidad individual en el espejo y le es posible desarrollar una comunidad. Se leen los enlaces entre la voz poética y otros personajes en la poesía de Rodríguez siguiendo el pensamiento reciente de los estudios de la discapacidad así como también de las ideas Kristeva sobre la discapacidad y las intervenciones de la fenomenología feminista. A pesar de que la poeta siempre ha negado una orientación feminista, las imágenes de la sangre menstrual y las alusiones al cuerpo de una mujer cisgénero en la poesía de Rodríguez hacen que este análisis sea inevitable. El artículo concluye observando las maneras en las cuales esta comunidad dentro de la poesía y la comunidad creada por la poeta misma catalogan y critican su contexto. La crítica Erin S. Finzer asevera que en este Período Especial:

los cubanos aguantaron los efectos de una extrema depresión económica que incluía tanto la carencia de las utilidades básicas, el petróleo, la comida y otros bienes materiales que en los tiempos anteriores se habían importado del Bloque Soviético como migraciones masivas debido a la privación económica. (232)

Las colecciones de Rodríguez que se examinan en este artículo están fundamentadas en la escasez del Período Especial. 
La primera etapa del desarrollo que se elabora en la poesía de Rodríguez es la chora. En este espacio primordial para desarrollarse que existe antes de que una persona empiece a usar el lenguaje. Está marcado por las funciones del cuerpo, y es esencial para la formación de la subjetividad y del deseo. Kristeva explica que es "a non-expressive totality formed by the drives and their states in a motility that is full of movement as it is regulated" (Revolution 25). Dicho de otra manera, la chora es un espacio provisional y móvil, fuera del tiempo y el espacio, y que crea al sujeto. Siguiendo la lectura de Kristeva que propone la crítica Noëlle McAfee, el espacio le pertenece al sujeto antes de desarrollar su identidad; sin embargo, es un espacio poco definido en la obra de Kristeva, y normalmente se traduce como una matriz (McAfee I9). Explica McAfee que la idea de Kristeva está basada en la chora de Platón, y en el pensamiento platónico la chora era el contenedor y productor del universo antes de que nada existiera (26). En la crítica literaria con una interpretación kristeviana, se puede pensar en espacios en los cuales un personaje, narrador o voz poética evoluciona.

En Páramos y La foto del invernadero, la voz poética utiliza un imaginario que es móvil, dinámico y fuera del lenguaje, características de la chora. En el poema "luz acuosa", por ejemplo, contempla su entorno con la voz del útero, una voz "blanda, matinal, grave, que te adormece por ser atendida / muellemente amada dentro de sí, drenado" (Rodríguez, Páramos 24). Según la crítica María del Mar López-Cabrales, "Este poema sirve de colofón a un simbólico rompecabezas picassiano" (68). Me gustaría ampliar su observación para postular que la voz poética, representando una matriz, es elíptica. La frase citada empieza con características que parecerían positivas, pero luego se nota que es un útero casi personificado por sus caracterización. Su reflexión se extiende hasta sus gatos. En "luz acuosa", la voz poética explica que "los gatos buscan también / alguna humedad y se dispersan sobre el cemento - ahora gris, después rojo" (Rodríguez, Páramos 22). Este cambio de color entre gris y rojo sugiere la caída de sangre, quizás menstrual, sobre el piso. También crea la sensación, para el lector, de que la voz poética está en su propio útero.

El poema "Imaginary Lancasted I: ella sobre el algodón, desnuda" hace eco de otro poema en la misma colección, "luz acuosa". Allí, la voz poética contempla una mancha en su casa que se convierte en una sombra, que interpreto como una matriz o chora ya que tiene una forma indeterminada y movimientos dispersos. El poema describe que la sombra es a la vez "rosada, rojiza, parda, un tono como ese de las tardes de verano cuajándose" (Rodríguez, Páramos 30). ${ }^{6}$ El género juega un papel importante en este poema. La sombra con olor y color es un espacio complejo y móvil. Esta caída nos regresa a un aspecto de la formación, la certidumbre otorgada por el cuerpo de la voz poética en un espacio como la chora. En "luz acuosa", la 
voz poética explica que sabía que: "yo era cierta a través de una capa / de olores puros, o ácidos, mezclados (olores que sobrepasan / cualquier ph, tierra, virilidad, feminidad; olores que un / perfumista esencial decidió combinar con tonos de rojos, fresa, claro, púrpura)" (Páramos 24). Dicho de otra manera, reconoce su existencia por el olor sangrante que supera conceptos binarios de género y equivalencias entre mujer y tierra; es más, los olores son casi diseñados o planeados para combinarse con varios colores posibles de sangre. El proceso de reflexión sobre la sangre en un espacio como una matriz es integral para la formación de la voz poética.

En los poemas de Rodríguez, la chora dinámica se relaciona con una atracción y repulsión; se asemeja a lo que Kristeva llama lo "abyecto", una etapa en que se establece una separación entre el sujeto y la chora. Según Kristeva, representa un deseo por esta separación a la vez que reconoce su imposibilidad (Powers of Horror IO, I4). Una crítica de Kristeva, Sara Beardsworth, sugiere que hay un contraste en su concepto: "On the one hand, abjection is a psychic differentiation from the mother's body ... On the other hand, it reveals the deepest collapse of selfhood" (82). En la obra de Rodríguez, el reconocimiento de dichas partes de la vida ocurre al mismo tiempo que la voz poética se contempla en su casa. Kelly Oliver, otra crítica de Kristeva, añade que lo abyecto es todo lo que nos atrae y que a la vez nos repele (Reading Kristeva 56-57). Es algo en la frontera entre conceptos opuestos que no respeta la tal frontera.

El concepto de lo abyecto es algo repugnante que provoca la separación que es necesaria para que alguien pueda desarrollarse. Finzer menciona que la poesía de Rodríguez entabla un diálogo con este concepto (238). Sin embargo, Finzer se enfoca más en la manera en la cual la poeta enfrenta la escasez económica a través de un lenguaje barroco y abyecto del útero sin abordar su rol en la formación de la voz poética misma. Además de formar parte del lenguaje barroco, "luz acuosa" reflexiona sobre la sangre de una manera tan extensa que resulta asquerosa. La sangre es crucial para que la voz poética llegue a entenderse a sí misma. La voz poética se expresa a través del lenguaje escrito, de la "línea / roja y lírica" de su sangre, es decir, la escritura del cuerpo (Rodríguez, Páramos 56). Nos hace recordar el cisne sangrante de la poeta uruguaya Delmira Agustini.7 El poema "ski sauvage", un esquí salvaje, profundiza sobre estas ideas. El título, en francés, sugiere tanto la influencia de la cultura no cubana en la poesía de Rodríguez como un movimiento brutal. La voz poética contempla su sangre que alude al movimiento del esquí en su casa: "ha cortado la pierna izquierda al rozar y yo, más que sufrir la herida, describo su dolor (estética)" (Páramos 56). Prefiere mirar la herida en el espejo "por donde sangr[a], primero / oliendo, tocando la burbuja que nace" (Páramos 56). Le fascinan los aspectos táctiles y visuales de su sangre. La conclusión del poema "ski sauvage" desafía a su público: “... ustedes / esperaban una historia. atrévanse a discernir si han / 
cabalgado sobre un ski sauvage, entre el ocio y la suavidad / de esa caricia con franja de obsenidad [sic] que es la escritura" (Páramos 57). Este poema asemeja la escritura a un deporte violento en vez de una actividad ligera; implica cierta curiosidad activa hacia su sangre. Es más, sugiere que los resultados de la escritura pueden ser tan peligrosos como los del esquí. Esta escritura entonces es el producto de la voz poética que sabe enunciarse a partir de la contemplación del olor y la textura de la sangre, es decir, de un aspecto abyecto de su cuerpo.

La voz poética también se atreve a mencionar otro aspecto de la experiencia femenina pocas veces discutida, el aborto espontáneo. En el poema "ella volvía", la voz poética presenta a un personaje, "ella", para meditar sobre este supuesto fracaso de su cuerpo:

ella volvía de su estéril landa,

bajaba las piedras antes de que aquella intensidad

se convirtiera en sangre

y todo aquel amor se convertía en sangre

bajaba por sus muslos (Rodríguez, Foto del invernadero 39)

La voz poética asemeja la falta de fertilización en la tierra a su incapacidad de lograr la fecundación en su útero con el resultado de que la sangre corra por sus muslos. La voz poética complica la tendencia en la historia de la literatura y del arte de equiparar la mujer a la tierra al explicar que la voz poética fecunda la tierra estéril con su flujo menstrual:

es el reto del paso

de lo profundo a lo sagrado

de lo efímero a lo eterno

porque esta intensidad se convertía en sangre

por su necesidad de ser libada en febrero

justo antes de la primavera (Foto del invernadero 39)

Este fragmento muestra que la sangre facilita cruzar fronteras entre lo tangible y lo intangible y la dificultad de este proceso. Implica también que o la sangre o la fertilización "liba" o ayuda a la voz poética en este proceso. Las descripciones implícitas y explícitas confirman, a mi modo de ver, el hecho de que la sangre en la vida de la voz poética tiene una función similar para la creación del sujeto al papel del concepto del abyecto en el proceso de desarrollo del sujeto concebido por Kristeva. Solo estas imágenes poderosas y sangrientas le son suficientes a la voz poética para expresarse.

Una función importante de las imágenes abyectas es la de ayudar a que la voz poética se separe de una visión anterior de sí misma, algo que ocurre cuando la voz poética se mira al espejo y en una foto antigua, probablemente 
de sí misma. En ambas situaciones, ella trata el envejecimiento de su cuerpo y regresa a una etapa primordial. Estas situaciones se asemejan a una etapa importante en la teoría psicoanalítica, la etapa del espejo, en que un individuo se separa de una imagen ideal de su ser. En el criterio de Kristeva, esta etapa del espejo ocurre después del proceso de desarollo que se relaciona con lo abyecto (Revolution 46). ${ }^{8}$ Explica que en este momento, cercano a la etapa en que los niños empiezan a hablar, se deja el mundo primordial de la chora para entrar al mundo (Kristeva, "The Semiotic and the Symbolic" 42).9

Páramos y La foto del invernadero exponen una relación entre la voz poética y su imagen en el espejo en que Rodríguez empieza una etapa nueva de madurez, marcada por su reconciliación corporal. Además de concordar con la etapa explicada por Kristeva, algunos poemas describen una segunda etapa del espejo en la vejez. Para la crítica Leni Marshall, el espejo facilita el reconocimiento de la vejez y la muerte al final de la vida, sobre todo para la mujer (53-54). En un intercambio de miradas en que la voz poética representa una méconaissance de la edad madura, la voz poética se mira. Se sorprende porque su reflexión "frente al espejo, un rostro serio de una mujer / madura me observa (escasez de los vellos del pubis, antes / muy negros)" (Rodríguez, Páramos I5). No se reconoce. Cree que lo que ve, "senos con bolas oscuras en las puntas (separados) como las / de tía Adelfa", son de otra persona (15). Tan extraña se siente en esta nueva etapa de su vida que prefiere asemejar la imagen a una pariente en vez de sí misma. Este ser extraño que percibe se desdobla, y la voz poética siente que hay "un yo (otro) detrás del cristal" ( 15 ). Se niega a reconocerse en su doble, insistiendo que en su reflexión cuando se desnuda, "no hay mí" (15). En esta falta de reconocimiento propio, experimenta trauma y sentimientos de pérdida.

Mirarse en el espejo es también un momento de celebración en la poesía de Rodríguez. Esta celebración concuerda con las ideas de la crítica Marshall, quien sostiene que la vejez provee una oportunidad para el reconocimiento autónomo pocas veces ejercido por la mujer en su juventud (6r). Leo el poema "mano de plata" siguiendo esta observación. La voz poética compara los vellos de su cuerpo con las algas del océano. Cuenta que siempre los había intentado esconder y que "sient[e] el horror del descubrimiento de los vellos de los brazos" (Rodríguez, Foto del invernadero ${ }_{67}$ ). El poema sugiere que tales vellos hacen que la voz poética no se asemeje a una mujer ideal. Se asombra al pensar que su pareja los mirara, visto que para ella esta mirada significaría que él mira hasta la profundidad del "infinito campo de [su] cuerpo" (67). La voz poética, quien ha intentado esconder partes de su cuerpo, tiene miedo de una relación íntima con su pareja, ya que con tal relación, él la viera tal y como es. Es más, su envejecimiento incluye comparaciones con su pareja: "soy más que él. mi delgadez, su arritmia, la oblación" (Rodríguez, Páramos i5). A la vez que se 
siente superior, tampoco es la mujer que era en su juventud. La voz poética lucha contra su vergüenza para reconciliarse con su reflexión en esta etapa de su vida y poder ser reconocida por su pareja en su vejez.

Recibe mayor reconocimiento propio a través de un diálogo con una foto en "los días", un poema que forma parte de una reflexión sobre la fotografía al igual que toda la colección La foto del invernadero. La poeta ha comentado esta colección en varias entrevistas. En una entrevista con Silvia Figueroa y Néstor E. Rodríguez, Reina María Rodríguez explica que "La foto de invernadero es un libro ... con una pátina de aparente reflexión ... [sobre] las páginas de la revista Correo de la Unesco (que ya creo no existe para pena de la humanidad)" ("En la casa"). La colección se basa en el Correo, usando sus fotos de varias partes del mundo, y, a partir de ellas, la colección construye un universo-invernadero. Dialoga con el teórico Roland Barthes, quien ha escrito sobre la fotografía y su relación con la muerte. La perspectiva de Rodríguez es distinta a la de Barthes porque la suya viene del subdesarrollo (Rodríguez, "Esta casa" 23). En uno de los poemas de esta colección, "los días", la voz poética contempla una antigua foto - de sí misma, no de la UNESCO - con tanta concentración que se asemeja a su contemplación frente al espejo. Recuerda: "eso era ser joven. cuando aún, verde y tibia / masticaba las ramitas de toronjil con indiferencia" (Rodríguez, Foto del invernadero 22). La voz poética se acuerda de los días en los cuales ella no tenía que masticar el toronjil para tener calma y vigor ni para suprimir el deseo de comer. ${ }^{\circ \circ}$ La joven en la foto representa una nostalgia por la juventud y por las épocas anteriores, en las cuales se tenía suficiente comida.

La voz poética también se empodera al reconocerse en la foto. Sobrepone su rostro al rostro de la joven en la foto:

es un rostro encarnizado en morir bajo la misma luz

donde ella y yo hemos permanecido

en lo curvado

en lo que ya no es mi juventud (Foto del invernadero 23)

La voz poética sueña con su cuerpo joven, porque sabe que le dio cierto poder. La contemplación frente a su imagen actual y una antigua foto en distintos poemas en la misma colección se yuxtaponen. Las reflexiones sobre estas etapas son cruciales para enfrentarse con su pasado y su momento actual.

En este espacio de memorias, la voz poética se vincula con otros personajes en su poesía a través de experiencias eróticas y metaliterarias. Estas conexiones reflejan también los esfuerzos de la poeta por crear espacios culturales a partir de su casa en la ciudad de la Habana. La 
presencia de la sangre en estos poemas se conecta con las perspectivas de los estudios de género y de discapacidad en la fenomenología feminista de Gail Weiss y Rosalyn Diprose y el ensayo reciente de Kristeva, "Liberty, Equality, Fraternity and ... Vulnerability". Representan un esfuerzo por establecer una nueva forma de vida en común.II

La sangre en la poesía de Rodríguez no exige ni necesariamente fomenta conexiones con otros. Sin embargo, en ciertas situaciones en la poesía, facilita relaciones entre el cuerpo de la voz poética y otros cuerpos. ${ }^{12}$ Kristeva hace observaciones en torno a las conexiones interpersonales y la discapacidad en su contexto, en Francia a principios del siglo XXI: "vulnerability reflected in the disabled person forms us deeply, or, if you prefer, unconsciously, and that as a result, it can be shared" (Kristeva, Hatred 30). Siguiendo esta línea de pensamiento, las discapacidades pueden ser importantes para establecer conexiones entre personas a partir de sus vulnerabilidades.

Para analizar el desarrollo de estos enlaces en los textos de Rodríguez me refiero también a la obra de las filósofas Weiss y Diprose. Las dos reflejan las influencias de la fenomenología de Maurice Merleau-Ponty, cuya visión de la intersubjetividad se basa en el contacto entre sujeto y objeto. Para Merleau-Ponty, un individuo llega a ser un sujeto no solo a través de la imagen en el espejo, sino también a través de su relación con todo lo visible (132-36). Weiss y Diprose sugieren que el proceso de llegar a ser un sujeto abarca la relación entre el individuo y las imágenes corporales de varias personas. Para Weiss, un sujeto se forma como tal a través de una relación dinámica con el cuerpo individual y a través de relaciones con las imágenes corporales de otros. El proceso de asumirse como sujeto es necesariamente, para Weiss, un proceso "inter-corporal" (53). De manera similar, Diprose asevera que el cuerpo se abre hacia otros en experiencias generosas, y que estas experiencias funcionan como el lugar en donde nacen la agencia y la percepción (69). En el caso de Páramos y La foto del invernadero, este sujeto supera al individuo racional. Existe en relaciones interdependientes, "intercorporales" y generosas.

El cuerpo anormal de la voz poética es generoso en experiencias eróticas y en enlaces metafóricos con teóricos y figuras históricas. En las experiencias eróticas quisiera destacar la generosidad de la mujer, para corregir el error cultural y social de subrayar la generosidad solo de cuerpos de hombres y de menospreciar o borrar la de las mujeres (Diprose 58). ${ }^{13}$ En las experiencias sexuales generosas, la voz poética tiene la posibilidad de ejercer su propia voluntad. A saber, "luz acuosa" cuenta un día normal en la vida de la voz poética. Esta mujer está en su casa, escribiendo, en un lugar ya establecido para reflexionar, mientras que su pareja está en el piso escapándose del calor. Súbitamente, pasando desapercibido por ella, él se levanta e inserta su "lengua fina" en la boca de ella, mientras que ella escribe 
(Rodríguez, Páramos 22). La voz poética, aunque no haya iniciado esta expresión, "vuelve a saborear" el beso de su pareja (22). Este beso se supera, llegando a un nivel más íntimo cuando la voz poética confiesa que su lujo es descansar en su hamaca "a la hora del mediodía, con el intenso / calor, abrir las piernas y dejar que esa lengua delgada ande / otra vez hurgando alli" (22). Este fragmento alude al hecho que esta experiencia le dio placer físico. Fue una experiencia compartida que, de acuerdo con Diprose, fue generosa. Pero se debe preguntar, ¿quién es generoso? ¿El que propone el acto o la que deja de escribir para participar en ello? Hay que reconocer la bondad de dejar de trabajar; es más, la experiencia erótica hace que la voz poética, y no solo el cuerpo, sea conocida por otro.

"luz acuosa" relata experiencias de generosidad más reconocidas que el hecho de que una mujer deje su trabajo. Considera devolverle el favor a su pareja y contempla su pene. Se pregunta: "un pene es / rosado? es sangre, resina de dragón? es sepia? tal vez siena / tostada" (Rodríguez, Páramos 25). Estas imágenes vienen de la vida cotidiana y de las características físicas de su pareja, salvo la resina de dragón, que conlleva una amenaza. El susto aumenta cuando la voz poética asevera que "tragué este semen con / miedo a envenenarme (no era distinto)" (25). Después de haber terminado, se siente realizada, diciendo, "pero igual, era único" (25). Ella gozaba del poder otorgado por poseerle en ella y la experiencia es un momento de reconocimiento. Efectivamente, concuerda con el pensamiento de Diprose, que es a partir de "inhabiting the world of the other's body ... that we can act ... have an identity" (69). En una experiencia similar en "mano de plata", se entrega a la experiencia erótica. Repite la frase, "sólo tú y yo", que sugiere un universo en el que viven solo los dos. Explica que juntos pueden atravesar "la hilera de diente-perros, los años, las diferen- / tes líneas de árboles mudos e iguales a lo largo de la infinita / distancia de una mano" (Rodríguez, Foto del invernadero 68). Se mezclan el micro-universo y el macro-universo. Proclama: "sólo tú y yo, podemos mezclar en este momento la ficción de / lo real y lo viviente entre las algas" (68). El momento singular de la mezcla sexual le permite conectarse con el cuerpo del otro y evocar, a través de las algas corporales, el océano. La experiencia erótica le quita su disfraz a la voz poética y le ayuda a expresarse como mujer a través de lo que Weiss llama una relación inter-corporal. Desde luego, la experiencia erótica es una experiencia generosa ¿de parte de quién? ¿Es mutua la generosidad?

La manera en la que los cuerpos se juntan permite nuevas formas de comunidad. Formar comunidad no es un proceso lineal, sino una experiencia de lo inesperado, lo que está fuera de control. Una parte de esta comunidad es literaria, entre la voz poética y las figuras nombradas por ella. Desde las sombras y los espejos, intervienen nombres de pensadores y personajes famosos de varios siglos. En "luz acuosa," por ejemplo, se 
menciona a Plantagenet, que alude a una familia real francesa; Stephen Dedalus, de Portrait of an Artist as a Young Man por James Joyce; Ricardo Reich, un economista norteamericano; Virginia Woolf, una escritora inglesa; Gérard de Nerval, un escritor y traductor francés; y Santa Teresa. De manera similar, en "é o nada que é tudo," se nombra a Fernando Pessoa, un poeta y crítico portugués, y sus heterónimos Álvaro de Campos, Alberto Caeiro y Ricardo Reis, y en "Imaginary Lancasted I: ella sobre el algodón, desnuda ...", a Roger Caillois, un intelectual francés (Páramos 25; 49-50; 3I). A estos personajes históricos y literarios, la voz poética agrega también sus amigos, "todos / muertos, muertos o prófugos" (Páramos 25). En esta comunidad, participan las "sensacionistas", y las trabajadoras, como "Clarise con su vestido verde" (25). Esta lista de nombres muestra la familiaridad de la poeta con escritores e intelectuales europeos y norteamericanos, y también con personajes literarios e históricos. Muestra el nivel de sofisticación de la poesía de Rodríguez. Es más, según Finzer, la inclusión de los amigos no literarios corrobora la valoración de figuras literarias masculinas y femeninas (24I). Se puede imaginar un mundo en que interactúan todos estos personajes como una comunidad metaliteraria; además, el énfasis en el cuerpo en la poesía de Rodríguez sugiere que estas interacciones son inter-corporales.

Además de los vínculos mencionados, la poesía crea espacios alternativos para el personaje de la voz poética, su pareja, y la comunidad artística de la Habana. La casa, además de ser un lugar para soñar, es un lugar para enfrentarse con los aspectos de su cuerpo que se asemejan a lo abyecto, en el espejo de la edad madura, y un lugar en el que se entrega a su pareja en un espacio comunitario. Es una alternativa a los espacios sindicalizados de la cultura, creados por el estado cubano. Es una heterotopia: "places outside of all places even though it may be possible to indicate their location in reality" (Foucault 24). Es un espacio que nos hace recordar las imágenes del útero-chora. Allí, la voz poética encuentra una luz "cuyo centro mismo es el vacío, punto de / ensanchamiento y entropía, donde todo se va y regresa" (Páramos 49). La casa de Rodríguez es el referente "real" para el espacio heterotópico en la poesía, y era necesario en el contexto de la producción de la poesía de Rodríguez. En el Período Especial, el momento de producción de la poesía de Rodríguez, Cuba era un país estancado, un país, según Deborah Meadows, de puertos sin barcos. De ahí que tenga sentido que la voz poética convierta su casa con cortinas de "tela / envejecida y floreada" en un barco (Rodríguez, Páramos 22-23). En este lugar apartado, puede soñar y vivir fuera de las demandas políticas o necesidades económicas. Rodríguez subraya la conexión entre su casa y un barco en una entrevista con Cristián Warnken. Asevera que no se siente recluida en Cuba, sino que "en mi caso es una situación también mental, salgo, recorro, estoy en un bote en medio del mar y de la nada con mi casa 
barco, pero tampoco salgo" (Rodríguez, "Reina María Rodríguez"). Aunque este barco no le trae a otro país, le da un espacio para huir de su realidad.

A través de su mediación del arte, llega al espacio en el que la realidad se disuelve y crea una forma de comunidad. Según "Imaginary Lancasted I: ella sobre el algodón, desnuda ...", "toda es ficción hasta que la mancha acelerada / cae y yo soy cierta" (Páramos 30). Es decir que la voz poética no sabe si existe hasta que una mancha, del mundo material y corporal, se mueve. Es más, como un útero es a la vez vacío y lleno de posibilidad, sigue un ejemplo conocido de la poesía cubana, el "tokonoma” en "El pabellón del vacío" del poeta José Lezama Lima, un lugar en que se escapa de situaciones difíciles. ${ }^{14}$ En este lugar, según la misma poeta, se resuelve "la antítesis é / o nada que é tudo" (Páramos 49). La voz poética, desarrollada a través de la chora, abyecto y espejo, en relaciones inter-corporales con otros, crea también espacios propios.

La poeta crea espacios que se asemejan a los espacios creados para intercambios dentro de su poesía. La poeta se asemeja a su voz poética creadora, ya que intenta existir en un espacio fuera de su contexto y crear espacios heterotópicos fuera de su contexto. La forma fragmentada de la poesía da forma a su comunidad. La poeta intentó crear una comunidad, independiente de las instituciones oficiales para la cultura (Cámara 223-24). Desafía los sindicatos creados por la mano peligrosa de la Cuba oficial, y opta por construir una ciudad separada en su azotea. La introducción a la sección de "La azotea de Reina" en la revista La Habana Elegante del verano de 1998 ilumina este ambiente:15

En la azotea de Reina María Rodríguez (en Ánimas no. 455 esq. San Nicolás, en Centro Habana) nos reuníamos frecuentemente sus amigos. Lo mismo si había o no había té, o si algún invitado extranjero nos llevaba ron y algunas galleticas, allí, casi como atraídos por el centro gravitacional de la poesía, comenzábamos las tertulias habituales. (Morán)

Era un espacio literario y cultural de intercambio entre cubanos y extranjeros, fuera de las estructuras oficiales. Tenía un carácter político no porque tuviera carácter de lucha, sino solo por el hecho de existir. Añade Morán que en la azotea se hicieron "[l]ecturas de poesía, la discusión de algún proyecto ... La azotea de Reina, como pronto comenzamos a llamarla, nos acogía a todos". Ella está orgullosa de haber tenido este espacio. Sin embargo, confiesa a Ponte: "Esta azotea es ahora un espacio vacío. De todos mis gatos quedan dos gatos viejos, Jorge, mi hija que ya es una muchacha. Cuelgo fotos de los amigos que se fueron, de los que se irán ... No puedo sustituir lo que fue, los que fuimos" (Rodríguez, "Esta casa" 25).

Ella intenta poner otros proyectos en el mismo espacio, pero sigue siendo un vacío sin las posibilidades que existen en el vacío poético. La 
llamada azotea de Reina, como salón cultural, estuvo ligada al Periodo Especial y, por eso, era un espacio heterotópico a corto plazo. El poema "El rasguño en la azotea" de Morán ahonda sobre el espacio. Explica que: "Inventamos una azotea para resguardarnos, pues nos creíamos las piedras sagradas de la ciudad - y tal vez lo éramos - mientras los gatos enfermaban de transparencia, iluminando en las noches sin ardor los platos vacíos" (Morán). La azotea les salvaba de un contexto de un alto nivel de escasez de comida. Los gatos parecían ser tan flacos hasta ser transparentes, una apariencia que iluminaba y se asemejaba a la falta de comida para los seres humanos. Había una conexión entre los seres humanos y los gatos, y juntos enfrentaron su situación.

Los espacios creados por Rodríguez en su vida y su poesía nos dejan con la esperanza de que otra forma de vida y arte son posibles. Páramos y La foto del invernadero compaginan con las ideas de la feminista chilena Nelly Richard sobre el arte. Ella propone que "el campo de la producción artística y cultural" necesariamente registra e interpreta "el efecto quebrantador y dispersante de la violencia social [en el] tejido comunitario" (76). La literatura, por ejemplo, emplea "sus dispositivos de lenguaje para comunicar un sentido bajo vigilancia por la censura administrada" (Richard 76). Este uso del lenguaje es posible a partir de la reflexión corporal que surge del útero-chora. Rodríguez refleja las tendencias del campo artístico imaginado por Richard, al retratar el Período Especial en varios poemas. ${ }^{16}$ En "luz acuosa", por ejemplo, asevera que su realidad parece ser "una masa caliente con exceso de tejido (sobreabundancia de / ser)" (Rodríguez, Páramos 23). Compara su ciudad a entrañas heridas: "mucosa prieta, útero que se ensancha y dilapida" (Rodríguez, Páramos 23). Las referencias al ser nos recuerdan al útero, hasta úteros dañados: "el ruido de mi ciudad es interior y gris, se ensancha - determinado por / las hormonas - que coloreas estos suburbios, las azoteas, / los entrepisos arenosos o metálicos del sentir" (Rodríguez, Páramos 23). Estas imágenes poderosas sugieren un útero que expande como en el embarazo y que se destruye en un aborto espontáneo. No hay referencias a las posibilidades positivas que conllevan las hormonas del útero. El uso de estas imágenes sangrientas resulta hasta asqueroso. Por eso, o por casualidad o por expreso, logra evitar algunas de las consecuencias de la censura o vigilancia. Así, al evocar de manera poderosa el fracaso social del Período Especial, se puede afirmar que esta poesía aumenta las posibilidades interpretativas mencionadas por Richard.

Las reflexiones sobre la sangre abyecta en "ski sauvage" y la vejez en el espejo en "Ídolo del crepúsculo" también forman parte de su juicio de su contexto. La voz poética asemeja las ruinas de su cuerpo a su ciudad fuera de control. El mismo poema profundiza sobre la sangre de la voz poética, describiendo la ciudad como un útero anormal que "se ensancha y dilapida y / llueve algunas veces aguas, otras sangre" (Rodríguez, "luz acuosa" 
Páramos 23). Forma parte de un útero-universo con nubes ensangrentadas que producen lluvias que prohíben el desarrollo humano normal. Cuando la voz poética abre su ventana, ve una masa sucia y menstrual, de "fango, sólo sangre, estiércol y sangre / coagulándose", que le da asco (Rodríguez "Ídolo del crepúsculo", Páramos i7). Este rechazo-atracción de su ciudad imita su rechazo-atracción de su sangre. Como afirma Dykstra, las múltiples menciones del cuerpo femenino en esta poesía reflejan la inestabilidad de una estructura social "in gradual halt [and] on the verge of a total meltdown" (I85). Estos fragmentos de poesía de una ciudad dañada se unen a la idea de una voz poética cuyo desarrollo se basa en las experiencias corporales. Es una denuncia clara de su ciudad en este momento, tanto como una denuncia de su país.

La poesía de Rodríguez también vincula imágenes de reparación de su cuerpo con la reparación de la ciudad por medio de las imágenes de su comunidad metaliteraria y su azotea. Eso sigue la línea de pensamiento de Kristeva sobre las posibilidades de intercambio y evolución dentro de la experiencia de la discapacidad (Hatred 32). Precediendo las observaciones de la teórica francesa, "luz acuosa" cuenta las varias maneras en las cuales la voz poética ha intentado parar esta sangre, con los objetos en su alrededor o de sí misma o de su hija, Elis. Usa "rellenos de algunos animales de Elis, / o muñecos de trapo, también lana. todo sirve aqui”" (Rodríguez, Páramos 23). Frente a esta realidad desconcertante, la voz poética no ve ninguna otra opción salvo el salir adelante: de ahí que mantiene que la ciudad "ha ensanchado sus paredes / rajadas (morfología de la célula) no se deja penetrar / fácilmente" (24). Reparar el cuerpo-ciudad empieza desde el útero e involucra a todos.

Los poemas, que equivalen la ciudad con un útero dañado, representan la cima de la búsqueda de la voz poética por entender su mundo y desafiarlo. Se puede imaginar el trabajo hecho y fortalecido por enlaces con otros en su azotea, en su casa-barco y entre sus amigos de su comunidad metaliteraria, es decir, de la comunidad literaria en la Habana y la comunidad imaginada a partir de personajes literarios. Su tarea crítica, que la voz poética misma describe como una página que "se llena / con signos del hastío para detener la muerte, o cambiar" (Rodríguez, Páramos 23), es un trance lúcido. ${ }^{17}$ Los elementos fuera de control forman la cima del proceso de desarrollo de la voz poética como individuo, con su pareja, y con su comunidad metaliteraria y material. El análisis de este proceso de desarrollo de una voz poética en dos colecciones de Reina María Rodríguez contribuye a ámbitos más amplios. Incluyen una valoración importante de la poeta dentro de la poesía cubana contemporánea escrita por mujeres, y la relación entre los estudios piscoanalíticos y los estudios de la discapacidad.

University of South Carolina 
NOTAS

I Para una reseña de la obra de Reina María Rodríguez, véase su entrevista con Antonio José Ponte, "Esta casa en el aire”. Más datos sobre su obra temprana se encuentran en el artículo de Bibiana Collado Cabrera, "Reina María Rodríguez: 'Hoy quiero escribir lo que me falta'”.

2 Algunas de las antologías en que aparece su obra incluyen Poetas cubanos actuales, editada por Daniuska González, y Cuba on the Verge: An Island in Transition, editada por Terry McCoy.

3 Los comentarios de Roberto Tejada contextualizan la obra de Rodríguez en su medio en el artículo "In Relation: The Poetics and Politics of Cuba's

Generation-8o", pp. 64-65.

4 Erin S. Finzer usa la teoría de Kristeva para acercarse a la obra de Rodríguez en su artículo "La endometriosis, el exceso y el Período Especial en la poesía de Reina María Rodríguez".

5 Para más información sobre este periodo véase Adriana Hernández-Reguant, ed., Cuba in the Special Period.

6 La mayoría de los poemas que se citan en este artículo son de prosa poética; se citan por nombre de la colección y página.

7 El artículo de Tina Escaja, "Modernistas, feministas y decadentes: Delmira Agustini, entre la mujer fetiche y la Nueva Mujer" ahonda sobre la sangre en la poesía de Agustini.

8 Beardsworth explica la etapa del espejo en la obra en Kristeva (62-76).

9 Luce Irigaray es otra teórica pisconalítica que ha escrito sobre el espejo y la vida de la mujer, sobre todo en The Speculum of the Other Woman (197).

IO De acuerdo con el análisis de Finzer, cuando los poemas en La foto del invernadero hablan de remolachas, otra comida, es también para mostrar relaciones con la escasez, ya que se las comía para evitar la anemia (240).

II La colección Libre acceso, editada por Susan Antebi y Beth Jörgensen, conecta los estudios de la discapacidad y los estudios latinoamericanos.

I2 Ato Quayson delinea los usos de la discapacidad en la literatura y la cultura en Aesthetic Nervousness (32-53).

I3 El artículo de Lilu Loofbourow, "The Female Price of Male Pleasure" provee más datos sobre la generosidad corporal en la cultura actual.

I4 José Lezama Lima (I9I0-1976) fue un poeta, cuentista y ensayista cubano. Su poema "El pabellón del vacío" describe la experiencia de una voz poética que abre un lugar secreto y vacío que llama "tokonoma”, en el que imagina cambiarse de lugar y cambios en su personalidad.

I5 La Habana Elegante fue una de las revistas cubanas más importantes a finales del siglo XIX (I883-I886). Era una revista principalmente literaria. A finales del siglo XX, un grupo de jóvenes intelectuales retomó el nombre para crear una revista electrónica con contribuciones académicas y de creación artística y 
literaria. Para mayor información, véase "Revista La Habana Elegante" y "Quiénes somos: La Habana Elegante, segunda época".

i6 El artículo de Elizabeth Hanly, "Cuba's Young Poets", explica la importancia del espacio creado en la azotea de Reina María Rodríguez.

I7 La crítica cubana Magaly Muguercia sugiere también una crítica colectiva de la sociedad cubana a nivel general en su artículo "The Body and its Politics in Cuba of the Nineties".

\section{OBRAS CITADAS}

A T TEB I, SUSAn, y BETH Jö RGE nSEn, eds. Libre acceso: Latin American Literature and Film through Disability Studies. Albany: SUNY P, 2016.

B EA R D W O RT H, SARA. Julia Kristeva: Psychoanalysis and Modernity. Albany: SUNY P, 2004.

CÁ mara, madeline. "Third Options: Beyond the Border." Trad. Javier MorilloAlicea. Bridges to Cuba - Puentes a Cuba. Ed. Ruth Behar. Ann Arbor: U of Michigan P, 1995. 217-25.

Co llad o C ABRera, B i i an a. "Reina María Rodríguez: 'Hoy quiero escribir lo que me falta."' Anales de Literatura Hispanoamericana 42 (2013): 8I-93.

Dip rose, ros alyn. Corporeal Generosity: On Giving with Nietzsche, Merleau-Ponty, and Levinas. Albany: SUNY P, 2002.

DYKSTRA, K RISTIN. "Afterword: The Only Moment I Will Witness." Violet Island and Other Poems. Trad. y ed. Kristin Dykstra y Nancy Gates Madsen. Los Angeles: Green Integer, 2004. I63-20I.

E SCAJA, tin A. "Modernistas, feministas y decadentes: Delmira Agustini, entre la mujer fetiche y la Nueva Mujer." Ciberletras i3 (2005). Web. S. pag.

FINZER, ERIN S. "La endometriosis, el exceso y el Período Especial en la poesía de Reina María Rodríguez." Letras Femeninas 35.2 (2009): 23I-54.

F o U C A U l T, M I C H E L. "Of Other Spaces.” Trad. Jay Miskowiec. Diacritics I6 (I986): 2227.

GonZÁlez, Daniuska, E D. Poetas cubanos actuales. Miranda: Ateneo de Petare, 1995.

hanly, elizabeth. “Cuba's Young Poets.” Partisan Review 63.I (1996): I4O-49. HERnÁ NDEZ-REGUANT, ADRIANA, ED. Cuba in the Special Period: Culture and Ideology in the I99os. New York: Palgrave-Macmillan, 2009.

I I I AR AY, LUCE. The Speculum of the Other Woman. Trad. Gillian C. Gill. Ithaca: Cornell UP, I985.

K R IS T E VA, J U L I A. Hatred and Forgiveness. Trad. Jeanine Herman. New York: Columbia UP, 2010.

-. Powers of Horror. Trad. Leon Roudiez. New York: Columbia UP, I982.

-. Revolution in Poetic Language. Trad. Margaret Waller. New York: Columbia UP, I984. 
—. "The Semiotic and the Symbolic." The Portable Kristeva. Ed. Kelly Oliver. New York: Columbia UP, 2002. 32-70.

LEZ A ma L I MA, José. “El pabellón del vacío." Cuba literaria. Ed. Alexander Pérez Heredia. 2018. Web.

L o o f в o row, Lili. "The Female Price of Male Pleasure." The Week 25 Jan 2018. S. pag. Web.

LÓPEZ-CABRALES, MARIA DEL mAR. "En busca de la palabra bajo una luz acuosa: la poesía de Reina María Rodríguez." Céfiro 2 (2002): 62-69.

MARSHALL, LEN I. "Through (with) the Looking Glass: Revisiting Lacan and Woodward in 'Méconnaisance,' the Mirror Stage of Old Age." Feminist Formations 24.2 (2012): 52-76.

MCA FE E, N OEL LE. Julia Kristeva. London: Routledge, 2004.

M C C OY, TERRY, E D. Cuba on the Verge: An Island in Transition. New York: International Center of Photography, 2003.

meadows, DEB oRAh. "The Poetics of Drifting Devotions: The Poetry of Reina María Rodríguez." Jacket 36 (2004). S. pag. Web.

MER LEA U-P ON TY, MAUR IC E. The Visible and the Invisible; Followed by Working Notes. Ed. Claude Lefort. Trad. Alphonso Lingis. Evanston: Northwestern UP, 1968.

M ORÁn, FRAn Cis co, Ed. “Sección: La azotea de Reina.” La Habana Elegante 2 (1998). S. pag. Web.

Muguercia, Magaly. "The Body and its Politics in Cuba of the Nineties." boundary 2 $29 \cdot 3$ (2002): $175-85$.

o LiVER, KE LLy. Reading Kristeva: Unraveling the Double-bind. Bloomington: Indiana $\mathrm{UP}, \mathrm{I} 993$.

QUay son, A 0. Aesthetic Nervousness: Disability and the Crisis of Representation. New York: Columbia UP, 2007.

"Quienes somos: La Habana Elegante, segunda época." La Habana Elegante 2 (2015). S. pag. Web.

"Revista La Habana Elegante." EcuRed, 20I8. S. pag. Web.

Richard, NE Lly. La estratificación de los márgenes. Santiago de Chile: Francisco Zegers, I989.

RODRíGUEZ, REINA MARÍA. “'Desire for Something that Doesn't Exist': Interview between Reina María Rodríguez and Kristin Dykstra." Trad. Kristin Dykstra. HOW2 I.7 (2002). S. pag. Web. 9 Mar 2009.

—. "En la casa de la poesía: encuentro con la escritora cubana Reina María Rodríguez." Entrevista con Silvia Figueroa y Néstor E. Rodríguez. Ciberletras 9 (2003). S. pag. Web.

-. "Esta casa en el aire." Entrevista con Antonio José Ponte. Encuentro con la cultura cubana 30/3I (2003-2004): 2I-26.

—. La foto del invernadero. La Habana: Casa de las Américas, 1998.

-. Páramos. La Habana: Ediciones Unión, 1995. 
—. "Reina María Rodríguez: La poesía como oxígeno y alimento." Entrevista con Cristián Warnken. El Mercurio de Chile. 15 May 2017. S. pag. Web.

TEjADA, Ro Berto. "In Relation: The Poetics and Politics of Cuba's Generation-8o." La detención del tiempo/Time's Arrest. Ed. Kristin Dykstra. Ottawa: Factory School, 2005. 59-73.

WEISS, GAIL. Body Images: Embodiment as Intercorporeality. New York: Routledge, I999. 